\title{
Perspective for Part II
}

\author{
Toshio Nakanishi
}

Pulmonary blood flow increases gradually during fetal life, and dramatic changes in the pulmonary circulation occur from the fetus to newborn, including decrease in pulmonary arterial resistance, increase in pulmonary blood flow, and closure of ductus arteriosus. Upon initiation of breathing after birth, pulmonary circulation is important for gas exchange between the alveoli and capillary vessels. Presence of congenital heart disease modifies development of the lung and pulmonary vessels, even before birth. For example, enlarged right atrium due to severe Ebstein's anomaly compresses the fetal lung and compromises lung development. Decreases in pulmonary blood flow during fetal life and especially after birth, for example, due to pulmonary stenosis or outflow stenosis may compromise the development of pulmonary arteries. In the research of morphogenesis of congenital heart disease, it is important to understand normal and abnormal lung and pulmonary vessel developments.

\subsection{Idiopathic Pulmonary Arterial Hypertension (IPAH)}

IPAH was discussed in this symposium because genetic background plays an important role and, therefore, IPAH is sort of a congenital disease. In IPAH, pulmonary smooth muscle cells and endothelial cells proliferate and obstruct small pulmonary arteries. Gene mutations such as bone morphogenic protein receptor II (BMPR II) are found in some patients with IPAH but the mechanisms how these gene mutations cause proliferation of pulmonary smooth muscle cells are still not clear. In addition to the genetic background, other factors such as inflammation may be involved because penetration rate of gene mutation is low.

\footnotetext{
T. Nakanishi $(\triangle)$

Department of Pediatric Cardiology, Tokyo Women's Medical University, Tokyo, Japan e-mail: nakanishi.toshio@twmu.ac.jp

(C) The Editor(s) (if applicable) and The Author(s) 2020 


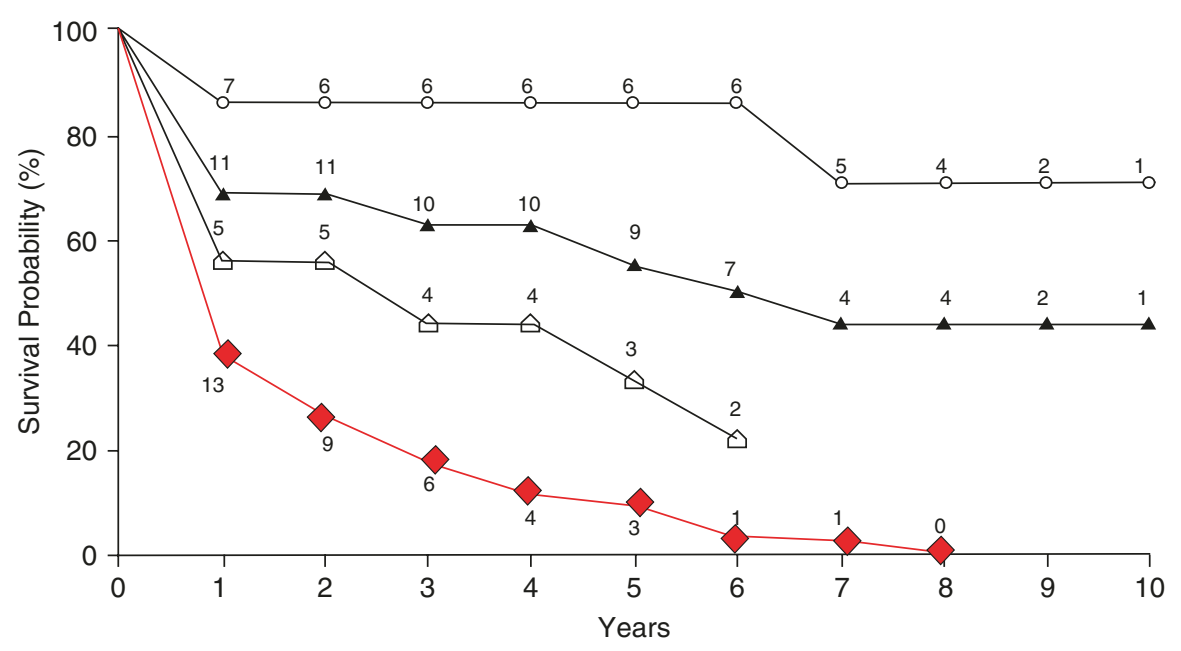

Fig. 14.1 Prognosis of pediatric IPAH. Red diamond: historical data before 1963. Open triangle: non-responders to acute prostanlandin $\mathrm{I}_{2}$ testing. Open sun: responders to acute prostanlandin $\mathrm{I}_{2}$ testing. Closed triangle: Patients who received pulmonary vasodilator therapy

Before pulmonary vasodilators were developed, calcium antagonists were the only drugs to treat IPAH, and prognosis of IPAH, especially pediatric IPAH, was very poor [1] (Fig. 14.1). In 1986, nitric oxide was found as a vasodilator, and after that various pulmonary vasodilators have been developed and used in patients with IPAH (Table 14.1). Time of government approval for clinical use differed in each country (Fig. 14.2). For example, intravenous epoprostenol was approved for clinical use in 1995 by FDA and in 1999 in Japan. It has not been approved in China at this moment in 2019. Prognosis of IPAH has improved depending on the time when a certain vasodilator could be used [2] (Fig. 14.3).

Use of pulmonary vasodilators improves prognosis of patients, but these drugs may not change the background pathophysiology of IPAH. Research to clarify the pathophysiology of IPAH is important to further improve prognosis of patients. Good animal models of IPAH are important to study the pathophysiology of IPAH and to develop a treatment strategy for IPAH. iPS cells have the potential to establish a good IPAH model in vitro.

To understand molecular mechanisms of IPAH, it may be important to clarify normal pathways governing morphogenesis of the lung and pulmonary vessels. If we can clarify how the lung and pulmonary vessels are formed, how each gene is involved, and how each signal transduction is involved, then we may be able know the precise mechanisms how pulmonary smooth muscle cells and endothelial cells start to proliferate and obstruct small pulmonary arteries in IPAH in the presence of gene mutations. 
Table 14.1 Pulmonary vasodilators

1. Endothelin pathway

Bosentan

Ambrisentan

Macitentan

2. Nitric oxide pathway

Sildenafil

Tadalafil

Riociguat

3. Prostacyclin pathway

Epoprostestenol

Iloprost

Treprostinil

Selexipag

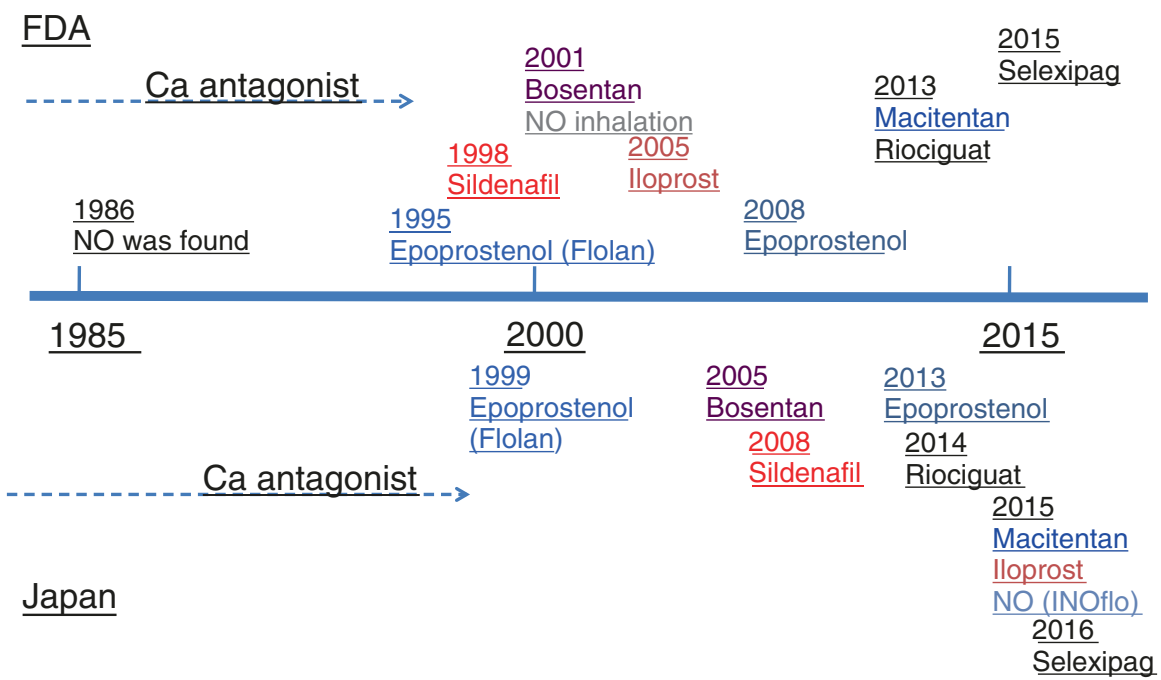

Fig. 14.2 Time of government approval for clinical use in USA (FDA) and in Japan. In 1986, nitric oxide was found as a vasodilator, and after that various pulmonary vasodilators have been developed and used in patients with IPAH 


\section{Comparison of primary endpoint between Group A, B, C, and D}

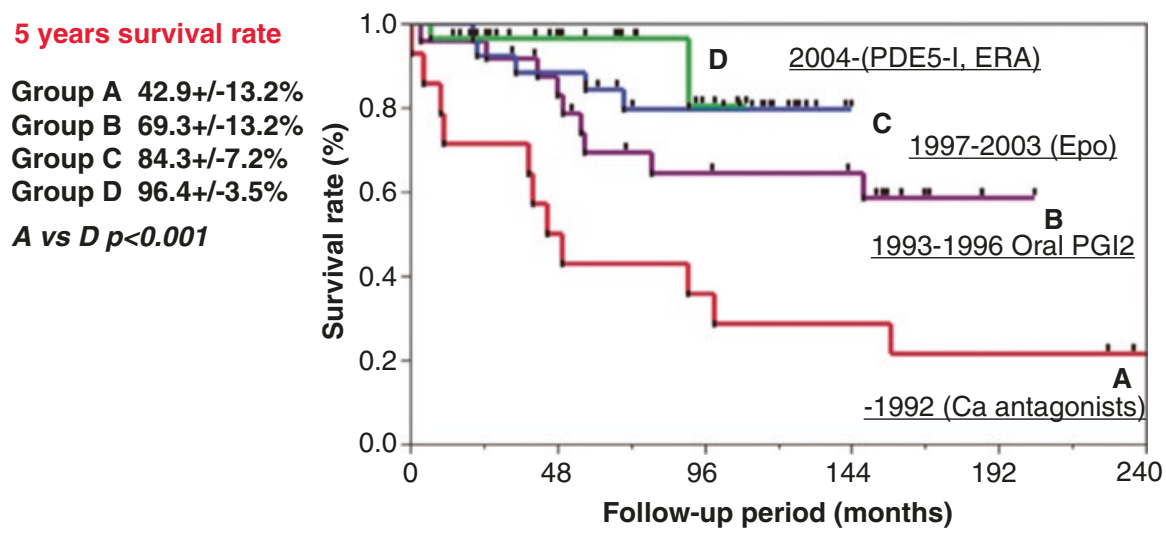

Fig. 14.3 Prognosis of pediatric IPAH in Japan. Prognosis of IPAH has been improved depending on the time when certain vasodilator could be used

\subsection{Pulmonary Hypertension with Congenital Heart Disease}

Fish has only one atrium and one ventricle. Frog and turtle have basically one ventricle and truncus, and yet it looks like they do not develop pulmonary hypertension although their blood pressure is low. Mammals have two ventricles and two circulations, systemic (left) and pulmonary (right) circulation, and if pulmonary blood flow is more than the systemic blood flow due to left to right shunt and if the pulmonary artery is exposed to high pressure, pulmonary smooth muscle cells and endothelial cells start to proliferate and obstruct vessels. We still do knot know the precise mechanisms for the proliferation of the pulmonary smooth muscle cells and endothelial cells in these conditions. The threshold of the "high pressure" is unclear but in human the pulmonary artery systolic pressure higher than $50 \mathrm{mmHg}$ can induce irreversible pulmonary obstructive disease. Once this condition has been established with the shunt remaining open, a relatively stable clinical condition continues until patients die earlier than a normal lifespan.

In IPAH and pulmonary hypertension with congenital heart disease, the right ventricle should tolerate increased afterload. Management of right ventricular contractile force is important in the treatment of patients with Eisenmenger syndrome and IPAH.

\subsection{Pulmonary Circulation in Patients with Congenital Heart Disease}

Fontan operation is performed if only one ventricle is functional in conditions such as tricuspid atresia, hypoplastic left heart syndrome, or single ventricle. Pulmonary circulation after Fontan operation is unique. In this operation, the right atrium is 
a

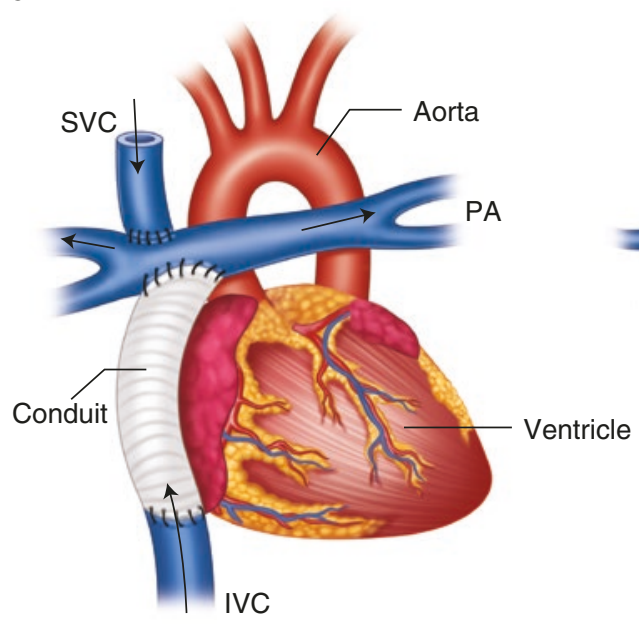

b

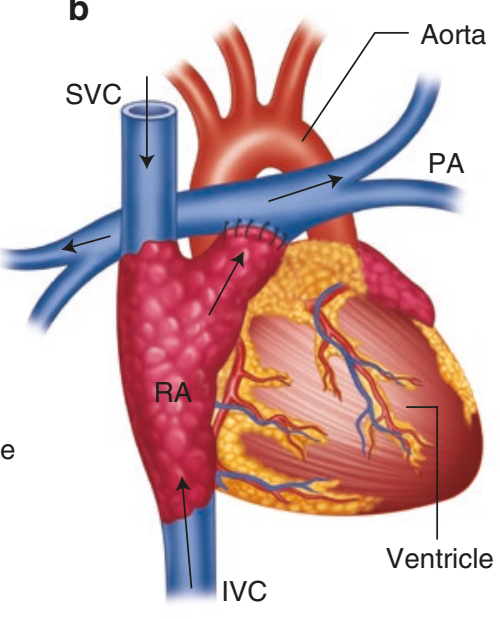

Fig. 14.4 Two types of Fontan operation. (a) Total cavo-pulmonary connection (TCPC). (b) Atrio pulmonary connection (APC). In TCPC, superior vena cava (SVC) is connected to the pulmonary artery (PA) and inferior vena cava (IVC) is connected with PA using conduit. In APC, right atrial appendage is connected with PA

connected to the pulmonary artery directly, or the superior vena cava and the inferior vena cava are connected to the pulmonary artery (Fig. 14.4). There is no pulsatile flow in the pulmonary artery after Fontan operation. After Fontan operation, pulmonary resistance can be slightly higher (3-5 Wood unit. $\mathrm{m}^{2}$ ) than normal (less than 3 Wood unit. $\mathrm{m}^{2}$ ). This slightly higher pulmonary resistance may compromise quality of life and lifespan of patients. The high pulmonary resistance may decrease pulmonary venous return, decrease cardiac output, increase central venous pressure, induce atrial ahhrythmia, increase liver congestion, induce liver cihhrosis, and/or induce protein losing enteropathy. Whether pulmonary vasodilators are effective in the management of Fontan patients is not yet clear. More importantly, molecular and cellular mechanisms of abnormal pulmonary circulation after Fontan operation have not been investigated and should be clarified in future.

\section{References}

1. Barst RJ. Primary pulmonary hypertension in children. In: Rubin LJ, Rich S, editors. Primary pulmonary hypertension. Marcel Dekker: New York; 1977. p. 179-225.

2. Saji T. Update on pediatric pulmonary arterial hypertension. Circ J. 2013;77:2639-50. 
Open Access This chapter is licensed under the terms of the Creative Commons Attribution 4.0 International License (http://creativecommons.org/licenses/by/4.0/), which permits use, sharing, adaptation, distribution and reproduction in any medium or format, as long as you give appropriate credit to the original author(s) and the source, provide a link to the Creative Commons license and indicate if changes were made.

The images or other third party material in this chapter are included in the chapter's Creative Commons license, unless indicated otherwise in a credit line to the material. If material is not included in the chapter's Creative Commons license and your intended use is not permitted by statutory regulation or exceeds the permitted use, you will need to obtain permission directly from the copyright holder.

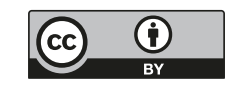

